\title{
Introduction: Understanding the Complexities of Eating, Drinking, and Surviving
}

\author{
Peter Jackson, Walter E.L. Spiess and Farhana Sultana
}

\begin{abstract}
This introduction to a series of essays on the global challenges of food and water security, commissioned as part of the International Year of Global Understanding, provides a definition of key terms and an historical context to these contemporary issues. It discusses the human right to adequate food and water, outlining some of the political struggles that have arisen over accessing these vital resources. Patterns of 'under-' and 'over-consumption' are discussed and analyzed, measured against the targets set in the Millennium Development and Sustainable Development Goals. The essays share a common approach, linking global challenges to the realities of everyday life and emphasizing the connections between biophysical and socio-cultural processes. The essays also address a number of cross-cutting themes including gender, ethnic and religious diversity, and the emotional and affective dimensions of life, going beyond questions of survival to incorporate the more qualitative dimensions of human well-being and quality of life.
\end{abstract}

Keywords IYGU • Eating - Drinking - Food security - Water security • Malnutrition • Obesity · Well-being • MDGs · SDGs

\footnotetext{
P. Jackson $(\bowtie)$

Department of Geography, University of Sheffield, Sheffield S10 2TN, UK

e-mail: p.a.jackson@ sheffield.ac.uk

W.E.L. Spiess

Institute of Food Process Engineering, Karlsruhe Institute of Technology,

Kaiserstr. 12, 76128 Karlsruhe, Germany

e-mail: rose-walter.spiess@t-online.de

F. Sultana

Department of Geography, Maxwell School, Syracuse University,

144 Eggers Hall, Syracuse, NY 13244-1020, USA

e-mail: sultanaf@maxwell.syr.edu

(C) The Author(s) 2016

P. Jackson et al. (eds.), Eating, Drinking: Surviving,

SpringerBriefs in Global Understanding, DOI 10.1007/978-3-319-42468-2_1
} 


\section{The Global Challenges of Food and Water Security}

According to the UN Food and Agriculture Organization, food security can be said to exist 'when all people, at all times, have physical, social and economic access to sufficient, safe and nutritious food to meet their dietary needs and food preferences for an active and healthy life'. ' While food insecurity was once associated mainly with low income countries, cast within a 'development discourse', it is increasingly seen as relevant to high- and middle-income countries as a result of a particular combination of circumstances. Commonly referred to as a 'perfect storm' (Beddington 2010), experts have warned of the combined effects of climate change (increasing extreme weather events such as floods and droughts), the pressures of population growth and urbanization on the availability of agricultural land, and the increasing global demand for meat and animal products, which are threatening to undermine the ability of current agri-food systems to feed a global population which it is estimated will increase from around 7.4 billion today to around 9.6 billion by 2050 (UN 2013). The need for sufficient clean water to meet the needs of both thirsty people and crops have also put enormous pressure on dwindling water resources, creating water crises in drinking water systems and irrigation systems, bringing into question how we manage surface and ground water sources. To cope with future challenges innovative solutions have to be sought. Within the same time period it is also estimated that there will be a quadrupling in the global economy, a doubling in the demand for food and fuel, and a more than $50 \%$ increase in the demand for clean water (Foresight 2011).

The spectre of population growth outstripping available resources especially in food insecure environments has been debated for many years. Writing before the Industrial Revolution had transformed the economies of Western Europe and North America, Malthus (1798/2008) described the tendency of population, when unchecked by war and famine, to increase geometrically while agricultural outputs tended to increase arithmetically. Responses to the imbalance of population and resources have varied from calls to restrict population growth by contraception and other means that Malthus would not have countenanced, to an emphasis on increasing agricultural yields through scientific and technological innovation. Whether increased outputs can be achieved without having an adverse effect on the environment is currently being debated by advocates and critics of 'sustainable intensification' (Garnett et al. 2013).

Periodic crises, such as the 2007-8 'spike' in food prices which was driven by the increasing cost of agricultural commodities (including key inputs such as pesticides and fertilisers), led to social unrest, food riots and trade restrictions, precipitating what UN Secretary General Ban Ki Moon called 'the worst food crisis in a

\footnotetext{
${ }^{1}$ The full definition can be consulted at http://www.fao.org/docrep/005/y4671e/y4671e06.htm (accessed 20 April 2016). As might be imagined, each clause in the definition has been fought over since the initial formulation was advanced at the World Food Summit in 1996. See Midgley (2013) for a genealogy of this complex process.
} 
Fig. 1 The 2007-8 spike in food prices. Source FAO

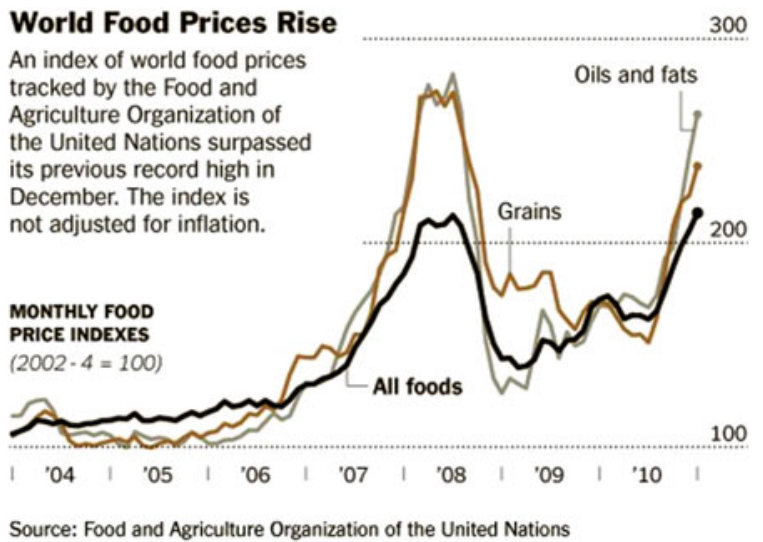

generation' (April 2008) (see Fig. 1). These issues reflect an underlying scarcity of food, water, and energy sources - to some extent because of a poor management of the available resources - as the world enters the period of 'peak oil' production. Magazines such as The Economist have reported on 'The end of cheap food' (6 December 2007) and 'The silent tsunami: the food crisis and how to solve it' (19 April 2008), while think-tanks such as the New Economics Foundation have discussed the dire consequences of future food shortages, predicting that even the most food-secure places might be as little as 'nine meals from anarchy' (Simms 2008).

While growing food requires water, more importantly for us to survive as a species we need to consume water. Water is the biologically-necessary and non-substitutable resource that makes life on this planet possible. To reproduce our own beings requires that humans have adequate access to clean, safe potable water. For societal growth, water has to be available for a variety of societal needssanitation, industry, irrigation, ecosystem reproduction. Water is thus a political, economic, cultural, legal, and spiritual entity, and it seeps across all boundaries, natural and social. Water has been fought over through history, but it has also been regulated through communal, religious, and political means. As water sources become contaminated, polluted, and depleted, the global demand on water has continued to rise. Growing water crises around the world have meant that some have easier access to necessary water while others do not. Over 800 million people do not have access to clean drinking water on a daily basis. This astounding number indicates the daily suffering that individuals and societies must endure for basic survival. To address this, the United Nations declared in 2010 that water was a human right. UN Resolution 64/292 states unequivocally that 'The right to safe and clean drinking water and sanitation is a human right that is essential for the full enjoyment of life and all human rights'. This means that states have an obligation to fulfil the right for their citizens. Global water justice movements, policymakers, citizens, and scholars worked hard to get the UN to ratify the resolution, and have been rallying stakeholders to ensure water security of individuals, households, and communities are met. However, ensuring water of adequate quantity, quality, 
reliability, affordability, and accessibility remain significant challenges around the world (Sultana and Loftus 2012). This is particularly true of the Global South, but increasingly so in wealthy countries (e.g., Flint, Michigan, USA).

Controlling water, whether through technology or market mechanisms, has resulted in increasing suffering of many. The steady rise in commodification and privatization of water around the world has meant that poor people are marginalized in accessing a basic human right. Governments often privatize water supply systems as part of loan conditionality of international aid donors. Poor communities often cannot afford the water they need for survival, thereby resorting to accessing contaminated water sources. More than 2000 children under the age of five die daily from water-related illnesses, especially from lack of sanitation and hygiene. The need to make clean water more accessible to all could not be more profound. The priorities to meet the daily water needs of a thirsty population are important for nation-states, but such concerns are often neglected until crises unfold (e.g., water-borne disease outbreaks). Cities and municipalities struggle to provide safe potable water in the face of infrastructural, financial, and coverage challenges. The famous Cochabamba Water Wars in Bolivia in 1999 resulted in global attention to the commodification and privatization of water that hurt the poor, demonstrating the interconnections between geopolitics, international aid, urban governance, and citizen disenfranchisement. In understanding the role that water plays in mobilizing people (when there is insufficient water) as well as creating apathy (when water is not of concern) can help us see the ways water is valued, managed, and how societies relate to one another.

As the preceding comments suggest, the scarcity of resources is compounded by problems of unequal access, whether in terms of gender disparities in access to food and water or in terms of the twin problems of 'over-consumption' (mainly in the Global North) coupled with 'under-consumption' (mainly in the Global South). For at the same time as there are more than 900 million undernourished people worldwide, there are growing numbers of overweight and obese people described by many as reaching epidemic proportions. ${ }^{2}$ The World Health Organization noted that more than 1.9 billion adults were overweight in 2014 (using the medical definition of those with a Body Mass Index of 25 or above), of whom more than 600 million were classified as obese (with a BMI of 30 or above). ${ }^{3}$ That 'under-consumption' is not restricted to the Global South can be demonstrated by the alarming rates of food poverty in even the most affluent countries. ${ }^{4}$ These issues have led to calls for a shift in emphasis from food charity to food rights (see, for example, Riches and Silvasti 2014). ${ }^{5}$

\footnotetext{
${ }^{2}$ Malnutrition is considered the greatest risk to public health (greater than HIV-AIDS, malaria and TB combined).

${ }^{3}$ For further details of how obesity and overweight are defined, see http://www.who.int/ mediacentre/factsheets/fs311/en/ (accessed 20 April 2016). For a critical account of the obesity 'epidemic', see Guthman (2011).

${ }^{4}$ For a discussion of First World food poverty, see Riches and Silvasti (2014).

${ }^{5}$ The right to an adequate standard of living, including adequate food, clothing and housing, was affirmed under the International Covenant on Economic, Social and Cultural Rights, a multilateral
} 
'Halving hunger' by 2015 was one of the UN's Millennium Development Goals (MDGs) which also included specific targets for improving child health, water and sanitation, women's reproductive health, reductions in epidemic diseases and improvements in education and networking. According to the UN's own evaluation and despite considerable progress in some areas, high levels of hunger were still found in sub-Saharan Africa and Southern Asia, with moderate level of hunger persisting in Western, Eastern and South-Eastern Asia, in Oceania, the Caucasus and Central Asia, and in Latin America and the Caribbean. The MDGs also sought to halve the proportion of the world's population without improved drinking water but, by 2015, 'low coverage' was still recorded in sub-Saharan Africa and Oceania, with only 'moderate coverage' reported in the Caucasus and Central Asia. Poor progress or deterioration was also noted in several parts of the world. ${ }^{6}$ The MDGs have now been superseded by a series of equally ambitious Sustainable Development Goals (SDGs) which include specific commitments to 'end hunger, achieve food security and improved nutrition and promote sustainable agriculture' and to 'ensure availability and sustainable management of water and sanitation for all' by $2030 .^{7}$

\section{Approaching the Issues}

Our approach in this publication is to emphasise the relationship between the global challenges of food and water security and the realities of everyday life for people in different parts of the world. We emphasise the practicalities of eating and drinking as social processes, undertaken in households and communities, besides the more abstract approaches to food and water taken by food scientists or hydrologists. Without underestimating the power of agri-food corporations and global trade agreements in shaping contemporary food systems, we emphasise the agency of ordinary people in meeting the daily challenges of 'feeding the family' (De Vault 1991). We also focus on the challenges involved in managing water which enables food to be grown, for families to have their right to water met for drinking, cooking, sanitation and survival needs, and for societies to access water that enables them to flourish and develop.

As with the other publications in this series, we emphasise the links between bio-physical and socio-cultural processes, and the connections between different geographical scales, from the most local decisions taken at household level to the

(Footnote 5 continued)

treaty adopted by the UN General Assembly in 1966. Several countries, including the US, have not yet ratified the Covenant.

${ }^{6}$ For an assessment of progress in achieving the MDGs, see http://www.un.org/millenniumgoals/ 2015_MDG_Report/pdf/MDG\%202015\%20PC\%20final.pdf (accessed 20 April 2016).

${ }^{7}$ For further information on the Sustainable Development Goals, see https:// sustainabledevelopment.un.org/?menu=1300 (accessed 20 April 2016). 
actions of transnational corporations that have truly global consequences. The authors and editors have experience of researching in many parts of the world (though we acknowledge the risk of ethnocentrism implicit in the current balance of power in academia reflected in the places from which the majority of our authors are drawn). We hope to increase the reach of our work through translating this English edition into Spanish and Portuguese (with further editions planned as soon as the necessary funds are secured). We also hope the Regional Action Centres associated with the IYGU will use this publication as a resource, debating its applicability to their own circumstances and proposing new avenues for future work to increase its global relevance.

Each essay has been written by someone with academic expertise in the area discussed but we have encouraged them to write in a style that is accessible to the general public, including an audience of students and teachers. With the cooperation of Ben Hennig and his colleagues at Oxford, we have included a series of illustrations from the Worldmapper project which uses specially-designed maps to highlight the extent of social and spatial inequalities that characterise our current agri-food systems. ${ }^{8}$ The maps provide a way of visualizing existing differences, making connections, thinking across scales and imagining alternative worlds, demonstrating the power of 'thinking geographically' (Jackson 2006). Authors have also been asked to explore alternative framings that challenge the conventional wisdom of orthodox ideas and approaches. How, for example, might the language of 'food security' shape the way we think about food poverty and inequality? How might these ideas be reshaped by adopting the language of food justice or food sovereignty? Each essay adopts a lively and argumentative approach, using evidence to make a case rather than being purely polemical.

Besides our substantive emphasis on eating and drinking, the essays also address a series of cross-cutting themes including gender, ethnic and religious diversity, and the emotional and affective dimensions of life which take the argument beyond questions of survival (as might be suggested by our title) into the more qualitative dimensions of human well-being and quality of life.

\section{Introducing the Essays}

The essays begin with an outline of the global inequalities that affect people's daily access to food and water in the Global North and South. Elizabeth Young highlights the 'cruel paradox' at the heart of the current agri-food system where under-nutrition in some places co-exists with obesity as a major public health problem in other places. She outlines the geographically uneven nature of hunger and the need to disaggregate data to reveal the various scales at which inequalities occur including social inequalities by age and gender. Young's essay raises

${ }^{8}$ For further information, see http://www.worldmapper.org (accessed 20 April 2016). 
questions of equity and entitlement, approaching food as a human right rather than as a matter of national and international security.

Trevor Birkenholtz takes a similar approach to the world's unequal access to drinking water, the scarcity of which disproportionately affects women. Drawing on the concept of 'modern water' as a calculable physical entity, divorced from its socio-cultural context, Birkenholtz argues that this technocratic way of thinking about water may exacerbate the problems of scarcity it was designed to eradicate. He suggests that the 'hydrosocial cycle' may be a preferable concept to the geo-engineering construct of the 'hydrological cycle', acknowledging the way that water supply development is embedded within wider issues of climate change, food security, natural disasters, healthy ecosystems, and livelihood well-being. While access to water has been improved in many parts of the world, the UN estimates that water scarcity affects around $40 \%$ of the global population, urban-rural disparities persist and new conflicts have arisen over the privatization and commodification of this most basic resource.

Jeroen Vos and Rutgerd Boelens mobilise the concept of 'virtual water' in their discussion of the relationship between water resources, agriculture and trade. The idea is to measure the amount of water 'embedded' in specific products, representing the water used (or contaminated) in its production. While the concept has academic and political value, drawing attention to the amount of water consumed in the production of export crops, frequently traded across considerable distances, it can draw attention away from local situations in which real as opposed to virtual water is a matter of life or death, where few if any alternative sources are available. The needs of agri-food corporations for water to produce high-value fruits and vegetables or other water-intensive crops such as bio-fuels put them in competition with the resource needs of local small-holders and other less powerful rural communities. As the regulation of water resources becomes increasingly transnational, these political struggles are likely to intensify.

In his essay on integrated water resources management, Olivier Graefe asserts that the problem of access to water is not primarily due to an overall scarcity of water, nor is it primarily a technical or ecological issue. Rather, Graefe maintains, it is a management problem whose roots extend back to colonial times and whose solution must be found in political-economic terms. Despite major achievements in increasing global access to water, Graefe highlights failures in policy initiatives such as the structural reform programmes that followed the Bretton Woods agreement and which gave rise to competition between the agricultural, industrial and drinking water sectors. Examining the 'new paradigm' of integrated water management which advocates the river basin as the most appropriate scale for water management, Graefe shows how water transfers between river basins, which currently affect some 120 million people worldwide, undermine this approach. Attention therefore turns to questions of governance and the reliance on environmental experts who may lack political and democratic legitimacy.

Focusing on water, sanitation and hygiene, Kathleen O'Reilly highlights the consequences of unequal access to these key resources for people's health and wellbeing. She shows how safe disposal of human waste and effective hygiene 
standards are key issues in the survival of vulnerable populations, especially children, where conditions at the household level have repercussions at the regional and national scale, ultimately affecting global-level inequalities in infant mortality. O'Reilly also shows how poor sanitation and access to clean water impact disproportionately on women, increasing the risks of bodily harm and emotional stress. A Community-Led Total Sanitation approach is one means of combatting these environmental health issues, providing people with the dignity of reasonable access to safe water and effective sanitation.

Walter Spiess outlines the present availability and outlook for food supply in the next decades based on data compiled by FAO working groups. Differentiating global data highlights the availability of major nutrients in food secure and disadvantaged insecure regions of the globe. A major problem is the increasing length and complexity of supply chains which has led to a growing disconnection between food producers and consumers, one of the major reasons for the current low levels of consumer trust in food (Kjaernes et al. 2007). ${ }^{9}$ Factors with a pronounced impact on food supply include the growing middle class in Developing as well as Transitional Countries who desire more animal-based food components like dairy and meat products and increased biofuel production. Both realities diminish the supply especially of grains for consumers; the increased meat production requires large amounts of grain-feed and is related to an increased emission of greenhouse gases while biofuel production diverts valuable raw materials from the human food chain. The increased demand for more raw materials to support the food supply for the growing world population requires the use of so far underutilized land reserves but also a more intelligent use of available resources.

Marisa Wilson contrasts the moral economy of food in socialist and post-socialist countries with countries that espouse a market-led neoliberal approach. She argues that the production and consumption of food raises moral issues because it is a social necessity rather than simply a commodity that is produced and traded for profit. Her essay raises ethical issues about 'eating well', often cast in terms of quality, taste and sustainability, all of which have moral implications. Through her research on Cuba, Wilson shows how the way people produce, exchange and consume food have impacts on their everyday lives. Throughout its history, food production in Cuba has been tied into a global economy, whether producing sugar for export to the US in the period before 1959 or for the Soviet Union after the Revolution. Today, Cuba relies heavily on imported food and it is unclear how the current period of normalization in its relations with the US will play out. Drawing on her own ethnographic work, Wilson suggests that (neo)liberal and (post)socialist moral economies currently co-exist in uneasy tension with practical consequences for people's everyday lives.

\footnotetext{
${ }^{9}$ Following a recent outbreak of Foot and Mouth Disease in the UK, the Policy Commission on the Future of Farming and Food (2002) argued that the current agri-food system was 'dysfunctional' because farming had become detached from the rest of the economy and the environment. Emphasising the need for reconnection along the supply chain, the report's authors argued that consumers no longer knew enough about what they eat and how it is produced.
} 
Turning attention to East and Southeast Asia, Matthew Kelly explores the process of change from a predominantly rice-based diet to one that includes an increasing volume of processed food, high in fats, salt and sugar. While famine and malnutrition have been reduced as a result of this so-called 'nutrition transition', it has had severe consequences in terms of rapidly increasing rates of obesity and associated non-communicable diseases such as diabetes, cardiovascular problems and diet-related cancers. Kelly debates the extent to which these changes have been driven by the expansion of industrialized agriculture and the growing reach of transnational corporations, keen to sell energy-dense foods to an expanding middle-class consumer market who aspire to Western-style diets. The dilemma, he suggests, is whether economic growth and food security can be achieved while avoiding the negative health and environmental impacts of large-scale dietary change.

In the following essay, Ann Bartos outlines an alternative framing to the dominant food security discourse, tracing the origins of the concept of 'food sovereignty' in the global social movement associated with La Via Campesina. Focusing on the case of Aotearoa New Zealand, Bartos argues that these concepts have a distinctive history as they travel between different places. She shows how Tourism NZ and the dairy company Fonterra have mobilised a particular 'geographical imaginary' in their marketing strategies based on the model of '100\% Pure New Zealand'. She then uses this framework to examine three basic premises of the food sovereignty discourse regarding the provision of safe, sufficient and nutritious food; its cultural appropriateness; and its encouragement of domestic production and self-sufficiency. Bartos concludes that each of these issues is problematic in the New Zealand case, undermined by inequalities of provision, the speciousness of 'consumer choice' in a national context that is dominated by two supermarket chains; and a range of environmental issues including the pollution of agricultural land and freshwater ecosystems.

In the final essay, Jonathan Cloke raises some fundamental questions about current levels of food waste, arguing that these are not a regrettable side-effect of current systems of production, distribution and consumption but that they are intrinsic to the profit-driven motives of contemporary agri-business. ${ }^{10}$ Advocating a food-systems approach, Cloke argues that over-supply is a systemic rather than an accidental feature of food businesses that seek to avoid empty shelves, insisting on cosmetic standards for the shape and appearance of produce, encouraging the purchase of larger pack-sizes and using promotional strategies such as buy-one-get-one-free - all of which are likely to lead to food waste either in-store or in people's domestic environments. The resulting food waste is often sent to landfill where it contributes to anthropogenic global warming through the generation of methane emissions and other greenhouse gases. Cloke challenges the 'productivist'

\footnotetext{
${ }^{10} \mathrm{~A}$ recent report by the Institute of Mechanical Engineers (IME 2013) estimated that between 30 and $50 \%$ of food produced globally never reaches a human stomach because of wastage on farm, during harvesting, processing and transportation, or in store and at home.
} 
orientation of contemporary food policy calling for more attention to corporate profits as the engine driving food and other resource waste.

While these essays are by no means comprehensive in their global or topical coverage, we hope they provide a useful overview of the current challenge of securing sufficient, safe food and water to meet the needs of the world's rapidly expanding population. We have sought to advance a critical perspective on these issues, emphasising political questions about distribution and equality as much, if not more, than questions of absolute scarcity. We have outlined a range of alternative formulations to conventional thinking about food and water security, such as food sovereignty and the hydrosocial cycle, discussing the moral and political economies of current agri-food systems and the need to take account of geographical variations in issues that are often cast at the global or national scale. We have emphasised the differential impacts of resource scarcities on men and women and on younger and older people, challenging conventional solutions that are cast in technocratic terms that ignore their socio-cultural, political and ethical dimensions. In calling for greater understanding of the challenges of food and water security, we advocate the need for theoretically informed, empirically grounded research that addresses questions of scale, focusing on the inter-connections between bio-physical and socio-cultural systems. These are some of the fundamental themes that underpin the International Year of Global Understanding and they are key to addressing the challenges of eating, drinking and surviving, now and in the future.

\section{References}

Beddington, J. (2010). Food, energy, water and the climate: A perfect storm of global events?. London: Government Office for Science.

De Vault, M. L. (1991). Feeding the family: The social organization of caring as gendered work. Chicago: University of Chicago Press.

Foresight. (2011). The future of food and farming: Final report. London: Government Office for Science.

Garnett, T., Appleby, M. C., Balmford, A., Bateman, I. J., Benton, T. G., Bloomer, P., et al. (2013). Sustainable intensification in agriculture: Premises and policies. Science, 341, 33-34.

Guthman, J. (2011). Weighing in: Obesity, food justice and the limits of capitalism. Berkeley and Los Angeles: University of California Press.

IME. (2013). Global food: Waste not, want not. London: Institute of Mechanical Engineers.

Jackson, P. (2006). Thinking geographically. Geography, 91, 199-204.

Kjaernes, U., Harvey, M., \& Warde, A. (2007). Trust in food: A comparative and institutional analysis. Basingstoke: Palgrave Macmillan.

Malthus, T. R. (1798/2008). An essay on the principle of population. Oxford: Oxford University Press (World Classics).

Midgley, J. L. (2013). Food (in)security in the global 'north' and 'south'. In A. Murcott, W. Belasco, \& P. Jackson (Eds.), The handbook of food research (pp. 425-438). London: Bloomsbury Academic.

Policy Commission on the Future of Farming and Food. (2002). Farming and food: A sustainable future. London: Cabinet Office. 
Riches, G., \& Silvasti, T. (Eds.). (2014). First world hunger revisited: Food charity or the right to food?. Basingstoke: Palgrave Macmillan.

Simms, A. (2008). Nine meals from anarchy. London: New Economics Foundation.

Sultana, F., \& Loftus, A. (2012). The right to water: Politics, governance and social struggles. London and New York: Routledge.

UN. (2013). World population prospects: The 2012 revision. New York: United Nations, Department of Economic and Social Affairs, Population Division.

Open Access This chapter is distributed under the terms of the Creative Commons Attribution 4.0 International License (http://creativecommons.org/licenses/by/4.0/), which permits use, duplication, adaptation, distribution and reproduction in any medium or format, as long as you give appropriate credit to the original author(s) and the source, provide a link to the Creative Commons license and any changes made are indicated.

The images or other third party material in this chapter are included in the work's Creative Commons license, unless indicated otherwise in the credit line; if such material is not included in the work's Creative Commons license and the respective action is not permitted by statutory regulation, users will need to obtain permission from the license holder to duplicate, adapt or reproduce the material.

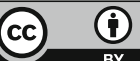




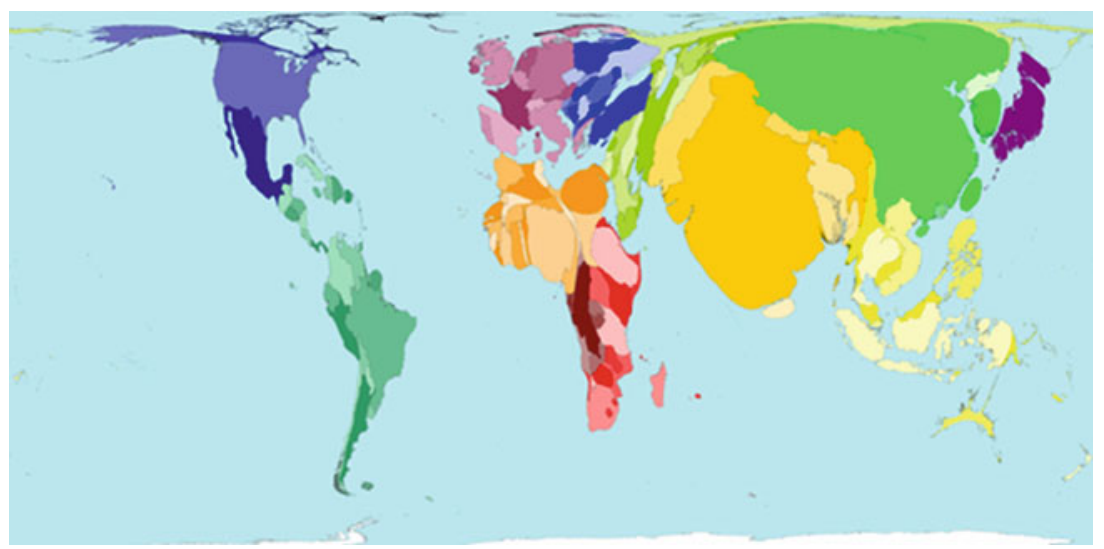

Total population. The distribution of the earth's population is shown in this map. The size of each territory shows the relative proportion of the world's population living there. Source www. worldmapper.org. Published with kind permission of (C) Copyright Benjamin D. Hennig (Worldmapper Project)

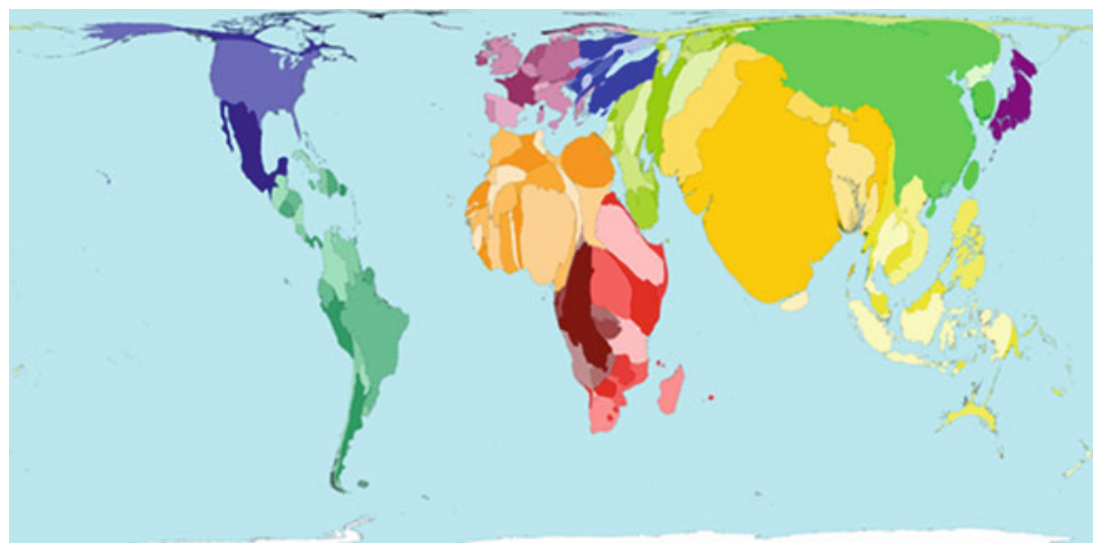

Population 2050. By 2050 it is estimated that the earth's human population will be 9.07 billion. $62 \%$ of the people will live in Africa, Southern Asia and Eastern Asia This map shows the predicted distribution for the estimated world population in 2050. Source www.worldmapper.org. Published with kind permission of (C) Copyright Benjamin D. Hennig (Worldmapper Project) 